\title{
Datos sobre la riboflavina ${ }^{1}$
}

\author{
R. Elaine Turner y Wendy J. Dahl ${ }^{2}$
}

\section{¿Por qué necesitamos la riboflavina?}

La riboflavina es una de las vitaminas del grupo B. También es conocida como la vitamina $B_{2}$. Nosotros necesitamos la riboflavina para utilizar los carbohidratos, grasas y proteínas en los alimentos que comemos. La riboflavina ayuda a utilizar estos nutrientes en energía para el cuerpo y para funciones como antioxidante. La riboflavina también se necesita para utilizar correctamente las vitaminas niacina, el ácido fólico y la vitamina $\mathrm{B}_{6}$.

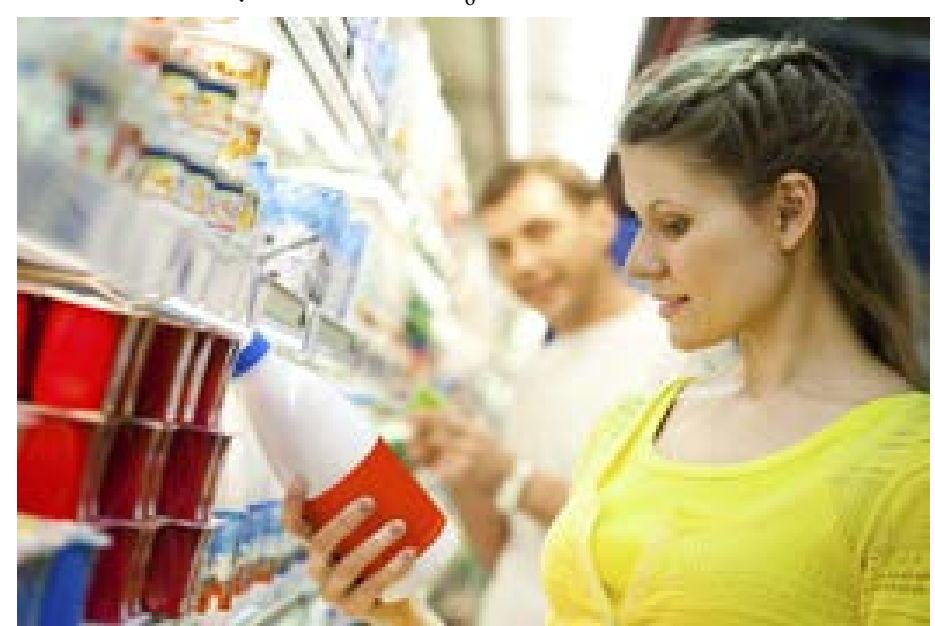

Figure 1. Dado que la riboflavina se encuentra en una variedad de alimentos, la mayoría de las personas obtienen suficiente en sus dietas

\section{¿Qué pasa si no consumimos suficiente riboflavina?}

Ya que ésta se encuentra en una variedad de alimentos, la mayoría de las personas obtienen suficiente en sus dietas. La deficiencia de riboflavina ocurre sólo cuando la dieta es muy pobre y carece de muchos nutrientes.

Los factores de riesgo de desarrollar una deficiencia de riboflavina incluyen el consumo crónico de bebidas alcohólicas y medicamentos. Se pueden realizar exámenes de sangre para diagnosticar si hay una deficiencia. La falta de riboflavina puede causar llagas en la boca, inflamación de la lengua e inflamación de la piel. La falta de riboflavina también puede afectar el uso que nuestro cuerpo hace con otras vitaminas.

\section{¿Cuánta riboflavina necesitamos?}

La tabla 1 muestra la cantidad recomendada diaria de riboflavina.

Tabla 1. Ingesta diaria recomendada de riboflavina en diferentes etapas de vida.

\begin{tabular}{|l|l|}
\hline Etapa de vida & Riboflavina $(\mathrm{mg} /$ día $)$ \\
\hline Hombres, edades 19+ & 1.3 \\
\hline Mujeres, edades 19+ & 1.1 \\
\hline Embarazo & 1.4 \\
\hline Lactancia & 1.6 \\
\hline & $\mathrm{mg}=$ miligramos \\
\hline
\end{tabular}

1. The English version of this document is FCS8668/FY211 Facts About Riboflavin. Este documento, FCS8808s, es uno de una serie de publicaciones del Departamento de Ciencias de la Familia, la Juventud y la Comunidad, Servicio de Extensión Cooperativa de la Florida, Instituto de Alimentos y Ciencias Agrícolas, Universidad de la Florida (UF/IFAS). Fecha de primera publicación noviembre de 2012. Visite EDIS en http://edis.ifas.ufl.edu/.

2. R. Elaine Turner, PhD, RD, profesora y decano asociada, College of Agricultural and Life Sciences; Wendy J. Dahl, PhD, RD, profesora asistente, Food Science and Human Nutrition Department, Universidad de la Florida, Gainesville, FL 32611. 


\section{¿Cómo podemos obtener suficiente riboflavina?}

La leche y otros productos lácteos son fuentes buenas de riboflavina. La riboflavina también se encuentra en granos enteros.

La riboflavina es una de las cuatro vitaminas que se añaden para enriquecer los productos hechos de granos tales como la harina enriquecida. Las otras vitaminas que se añaden a los productos hechos de granos enriquecidos son la tiamina, niacina y el ácido fólico.

Los cereales y los panes enriquecidos contienen riboflavina. Busque la palabra "riboflavina" en la lista de ingredientes de la etiqueta para ver si ha sido agregada:

INGREDIENTES: Sémola enriquecida (hierro, mononitrato de tiamina, ácido fólico, riboflavina, niacina), tomate, remolacha y espinaca en polvo ...

Otras fuentes buenas de riboflavina son: carne, huevos y champiñones.

La tabla 2 muestra algunos alimentos y la cantidad de riboflavina que contienen.

Tabla 2. Ejemplos de alimentos y los miligramos por porción de riboflavina.

\begin{tabular}{|l|c|}
\hline \multicolumn{1}{|c|}{ Alimento } & $\begin{array}{c}\text { Riboflavina } \\
\text { (mg por porción) }\end{array}$ \\
\hline Yogur, $8 \mathrm{oz}$ & 0.5 \\
\hline Leche, 1 taza & 0.4 \\
\hline Cereal listo para comer, 1 taza & 0.4 \\
\hline Huevo, cocido, 1 grande & 0.3 \\
\hline Chuleta de cerdo, cocida, $3 \mathrm{oz}$ & 0.3 \\
\hline Champiñones, cocidos, $1 / 2$ taza & 0.2 \\
\hline Requesón, $1 / 2$ taza & 0.2 \\
\hline mg = miligramos & \\
\hline oz = onzas & \\
\hline
\end{tabular}

\section{¿Cómo deben ser preparados los alimentos para retener la riboflavina?}

La riboflavina se destruye fácilmente cuando está expuesta a la luz. La leche almacenada en un recipiente de vidrio y expuesta a la luz pierde mucho su contenido de riboflavina. Las jarras de plástico opacas y envases de cartón protegen la riboflavina en la leche. Solo pequeñas cantidades de riboflavina se pierden durante la cocción.

\section{¿Qué pasa con los suplementos?}

Debido a la práctica del enriquecimiento de los granoscereales, la mayoría de las personas en los Estados Unidos obtienen suficiente riboflavina en su dieta, por lo que los suplementos no son usualmente necesarios. La mayoría de los suplementos multivitamínicos contienen riboflavina.

Las investigaciones aún no han encontrado problemas con el consumo excesivo de riboflavina proveniente de alimentos o suplementos. Sin embargo, no hay necesidad de tomar suplementos con más de $100 \%$ a $150 \%$ del valor diario de riboflavina.

\section{¿Dónde puedo obtener más información?}

El agente de Ciencias de la Familia y del Consumidor (FCS) en la oficina de extensión de su condado puede tener más información escrita y clases de nutrición para que usted asista. Además, un dietista registrado (RD) puede proporcionarle información confiable.

Más información nutricional confiable se puede encontrar en los siguientes sitios del Internet:

http://fycs.ifas.ufl.edu

http://www.eatright.org

http://www.nutrition.gov 
Copia de archivo: para las recomendaciones actuales, consulte http://edis.ifas.ufl.edu o su oficina de extensión local. 
Copia de archivo: para las recomendaciones actuales, consulte http://edis.ifas.ufl.edu o su oficina de extensión local. 
Copia de archivo: para las recomendaciones actuales, consulte http://edis.ifas.ufl.edu o su oficina de extensión local. 